\title{
An Ozonolysis Based Method and Applications for the Non-lethal Modification of Insect Cuticular Hydrocarbons
}

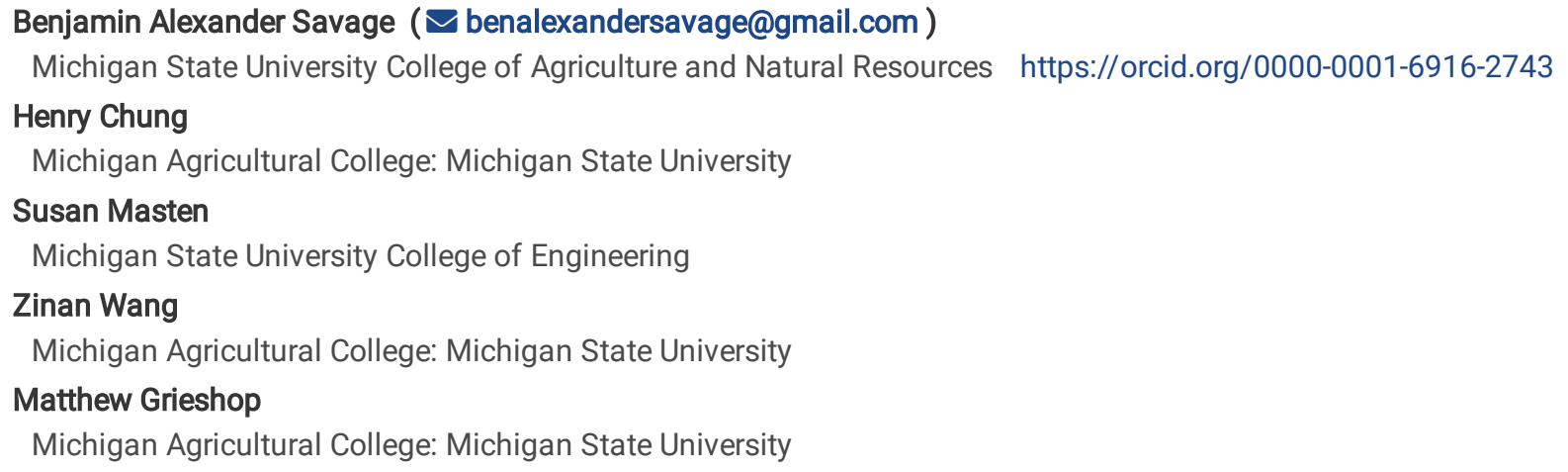

\section{Research Article}

Keywords: Cuticular hydrocarbons, modification, ozone, Drosophila suzukii, desiccation resistance

Posted Date: March 18th, 2021

DOI: https://doi.org/10.21203/rs.3.rs-299480/v1

License: (c) This work is licensed under a Creative Commons Attribution 4.0 International License. Read Full License 


\section{Abstract}

Cuticular hydrocarbons (CHCs) are important, multi-function components of the insect epicuticle. In Drosophila spp., CHCs provide protection from desiccation and serve as semiochemicals for both intra- and interspecific communication. We developed a non-lethal method for the modification of Drosophila CHCs profiles through the exposure of live insects to a high dose of ozone gas ( 45,000 ppm). Drosophila suzukii that were treated with ozone showed a 1.63-3.10 fold reduction in unsaturated hydrocarbons with these CHCs shown to regenerate over 108 h. Changes in CHCs were correlated with significantly reduced desiccation resistance in both male and female $D$. suzukii at one h after ozone treatment. Interestingly, individuals treated with ozone showed increased desiccation resistance in comparison to controls at $108 \mathrm{~h}$ after ozone treatment. The methodology reported in this paper provides a novel approach to investigate the biosynthesis and functions of $\mathrm{CHCs}$ during the lifespan of an insect.

\section{Introduction}

The Drosophila spp. epicuticle contains a wide range of saturated, unsaturated, and branched hydrocarbons broadly defined as cuticular hydrocarbons (CHCs) (Bartelt et al. 1986; Jallon and David 1987; Howard et al. 2003; Howard and Blomquist 2005). Drosophila CHCs form a waxy layer on the cuticle that reduces desiccation as well as provides inter- and intra-specific chemical signaling (Chung and Carroll 2015). It has been hypothesized that insect cuticular desiccation resistance decreases as epicuticular lipids change from a solid to liquid state (Ramsay 1935; Hadley 1994; Gibbs 1998). Unsaturated and methyl branched alkanes melt at lower temperatures compared to saturated hydrocarbons (Gibbs and Pomonis 1995). Therefore, saturated hydrocarbons are hypothesized to confer greater cuticular desiccation resistance than unsaturated hydrocarbons at higher temperatures (Gibbs 1998). For example, D. pseudoobscura dwelling in arid regions had a greater abundance of long-chained saturated hydrocarbons than laboratory maintained colonies, which correlates to a lower water loss rate (WLR) (Toolson and Kuper-Simbron 1989).

Previously, ozonolysis of $\mathrm{CHCs}$ have been used to identify double bond positions of unsaturated hydrocarbons on dipteran and hymenopteran cuticles following extraction using chemical solvents (Bartelt et al. 1982, 1986; Antony et al. 1985). Beroza and Bierl (1967) developed a method which uses ozonolysis to identify insect unsaturated hydrocarbons. This methodology involves extracting $\mathrm{CHCs}$ with a non-polar solvent and then treating the extract with ozone prior to gas chromatography-mass spectrometry (GC-MS) analysis (Beroza and Bierl 1967). Antony et al. (1985) demonstrated that monoenes and dienes extracted from Drosophila melanogaster undergo cleavage via ozonolysis to varied extents. For example, the researchers noted a "major" reduction in 7(Z)-tricosene after ozonolysis, while 9(Z)-tricosene experienced a "minor" reduction (Antony et al. 1985). However, ozonolysis of CHCs on live insects has not been previously reported. If ozonolysis can disrupt CHCs on live insects, this will allow us to investigate how changes to the $\mathrm{CHC}$ layer can affect desiccation resistance as well as chemical signaling in many insect species that do not have established molecular methods to disrupt these $\mathrm{CHCs}$, opening the doors to further discoveries in basic and applied research. We use Drosophila suzukii as a model for our experiment because $D$. suzukii or spotted-wing drosophila is a fruit fly species that has invaded many temperate fruit growing areas, causing hundreds of millions of dollars of damage annually to fruit crops in the United States alone (Bolda et al. 2010). Understanding how ozone can affect D. suzukii may lead to novel methods to control this pest. The $D$. suzukii $\mathrm{CHC}$ profile is largely sexually monomorphic, but small differences in compound abundance have been observed between males and females (Dekker et al. 2015; Snellings et al. 2018). D suzukii has a large variety of CHCs present, including monoenes (unsaturated hydrocarbons), dienes (unsaturated hydrocarbons) and n-alkanes (saturated hydrocarbons) with 7(Z)-tricosene being the most prevalent CHC in D. suzukii (Dekker et al. 2015; Snellings et al. 2018). Our study has three objectives. First, we will determine if ozonolysis affects $\mathrm{CHCs}$ on living $D$. suzukii. Secondly, we will evaluate the duration of these effects on $\mathrm{D}$. suzukii and whether $\mathrm{CHCs}$ will be regenerated after the initial ozonolysis. Thirdly, we will determine whether modifications to CHCs via ozonolysis affects D. suzukii desiccation resistance. We hypothesize that ozonolysis of unsaturated hydrocarbons will occur after an ozone treatment, that $\mathrm{CHC}$ 's will recover over time and that $\mathrm{CHC}$ ozonolysis will reduce desiccation resistance.

\section{Materials And Methods}

We performed two experiments to address our objectives. In experiment 1 we evaluated the effects of ozone on the CHCs of $D$. suzukii and the duration of these effects. Experiment 2 explored the effect of ozone exposure on the desiccation resistance of $D$. suzukii.

\section{Colony Details \& Maintenance}

Drosophila suzukii were sourced from a colony reared out of tart cherries (Prunus cerasus) collected from the Trevor-Nichols Research Center located in Fennville, Michigan in 2015. Flies were maintained on $5 \mathrm{~mL}$ of solid diet (Dalton et al. 2011) in $50 \mathrm{~mL}$ polystyrene vials (Lab Express, Cat. \# 8002-cs). The colony chamber was set on an 8-h dark period to a 16-h photoperiod, while maintaining an average relative humidity of $77 \%$ and temperature of $23^{\circ} \mathrm{C}$. 
Newly emerged flies were collected, separated by sex, and placed into vials with $5 \mathrm{~mL}$ of solid diet (Dalton et al. 2011) where they were allowed to age (3-5 d or 9-11 d) prior to experiments. Thirty to sixty aged flies of a single sex were transferred using a small paintbrush and forceps into 304 stainless steel cages for ozone exposures. Steel cages were fabricated from half of a $5.33 \mathrm{~cm}$ diameter spherical tea infuser (Fu Store, 8541896633) that was folded back onto itself to create a "clamshell". Stainless steel was used due to its low reactivity with ozone. All tools and surfaces were cleaned with $70 \%$ ethanol between each experimental run/treatment to minimize the chance of contamination.

Flies in experiment 1 were anesthetized with carbon dioxide before being placed into stainless steel cages for treatment and, after treatment, into new vials with diet. Flies in experiment 2 were aspirated from vials containing diet into stainless steel cages for treatment and into new vials with diet after treatment application. The difference in handling procedures between experiments 1 \& experiment 2 was due to the extremely low humidity of the carbon dioxide anesthetizing gas, which could directly affect the outcome of the desiccation trial (experiment 2). After ozone exposure, flies from both experiments were maintained in the colony chamber described above.

\section{Ozone Treatment Application}

An ozone generator (Absolute Ozone, NANO) applied 45,000 ppm of humidified ozone by using $99.5 \%$ oxygen as a feed gas at $14 \mathrm{psi}$ and a flow rate of $5.1 \times 10^{-5} \mathrm{~m}^{3} / \mathrm{s}$. Ozone was humidified by passing it through $100 \mathrm{~mL}$ distilled water in a $250 \mathrm{~mL}$ glass gas washing bottle before the gas entered the treatment flask (Fig. 1.). Flies were exposed to ozone for 5 seconds in a specially modified, glass $250 \mathrm{~mL}$ Erlenmeyer flask with a dorsal 29/42 ASTM ground glass joint and a lateral 34/45 ASTM ground glass joint which acted as a port to allow insertion of stainless-steel cages (described above). Control flies were treated with humidified oxygen ( $99.5 \%$ purity) for 5 seconds and handled in the same fashion as the ozone treated flies, while untreated flies were not exposed to ozone nor oxygen. Gaseous ozone concentrations were measured during treatment applications using an ozone monitor (2B Technologies, Model 106-H). Relative humidity and temperature of oxygen treatments inside the treatment chamber were monitored using an electronic hygrometer sensor (Sensirion, EK-H4).

\section{CHC Collection and Analysis}

Five flies of the same treatment and sex were placed into a $1 \frac{1}{2}$ dram glass vial (Kimble Glass Incorporated, Art. No. 60910L 12) along with 200 $\mu \mathrm{L}$ of a hexane wash. The hexane wash contained an internal standard of $25 \mathrm{ng} / \mu \mathrm{L}$ hexacosane (Sigma-Aldrich, \#241687-5G). The hexane wash was added to the glass vials with $100 \mu \mathrm{L}$ calibrated glass pipets (VWR International, Cat. No. 53432-921) and an aspirator (VWR International, Cat. No. 53432-921). Flies were left in hexane for 10-15 minutes. Samples were then placed on a mini-vortex (Fisher Scientific, Cat. No. 12-810-1) for 30 seconds at a vortex rate of 5 ( 1,800 rpm). The hexane solution was transferred into a $0.25 \mathrm{~mL}$ glass insert (Supelco, Cat. No. 24717) inside a $2 \mathrm{~mL}$ glass vial (Supelco, Cat. No. 27330) for GCMS analysis. The $2 \mathrm{~mL}$ glass vials were capped with 9 $\mathrm{mm}$ Blue S/T Caps (Supelco, 29044-U). Samples were stored in a $-20^{\circ} \mathrm{C}$ freezer (Fisher Scientific, Cat. No. 13986149) prior to and after GC-MS analysis.

Samples were eluted through a DB-17HT column (Agilent Technologies, Part No. 122-1831) that had a length of $30 \mathrm{~m}$, a diameter of 0.25 $\mathrm{mm}$, and a $0.15 \mu \mathrm{m}$ thickness. Helium was used as a carrier gas at a rate of $1 \mathrm{~mL} / \mathrm{min}$ through a GC-MS (Agilent Technologies, 5975C Series GC/MSD). Samples injected into the GC-MS were eluted after a four-minute solvent delay and a starting oven temperature of $50 \mathrm{C}$ that increased by $4 \mathrm{C} / \mathrm{min}$ until a final temperature of $300 \mathrm{C}$ was attained. The temperature remained constant for 10 minutes once $300 \mathrm{C}$ was reached.

Integration and quantitation of peak areas were determined by using the QuanLynx program of the MassLynx MS Software version 4.2 to evaluate total ion chromatograms (Waters 2020). After determining peak areas, the total area of each peak per sample was divided by the total number of flies (5) from each sample to give a mean estimate of cuticular hydrocarbon mass per fly. The mass of each compound was calculated by referencing the peak area of hexacosane $(5,000 \mathrm{ng})$, the internal standard (IS).

\section{Experiment 1: Ozonolysis of Hydrocarbons}

\section{Comparison of unsaturated hydrocarbons, aldehydes and saturated hydrocarbons $1 \mathrm{~h}$ after ozonolysis}

The CHC profile of 3-5 and 9-11 d old male and female flies were compared (4 groups total). Treatments consisted of an untreated control, oxygen treatment ( $99.5 \%$ purity) and an ozone treatment (45,000 ppm) (Table 1). Treatments followed procedures outlined in section 2.3 Ozone Treatment Application. Total amount, in nanograms (ng), of unsaturated hydrocarbons (5(Z)-tricosene, 7(Z)-tricosene, 9(Z)tricosene/tricosane, 5(Z)-pentacosene, 7(Z)-pentacosene, 9(Z)- pentacosene), aldehydes (heptanal, nonanal, tetradecanal, pentadecanal, hexadecanal, octadecanal) and saturated hydrocarbons (heneicosane, heptacosane, 2-methyl octacosane, nonacosane) peaks were quantified from $\mathrm{CHC}$ extracts from living flies $1 \mathrm{~h}$ after treatment application. 
Collection and analysis of hydrocarbon extraction samples followed the procedures explained in section 2.4. The masses of unsaturated hydrocarbons, aldehydes and saturated hydrocarbons were collected from five cuticular hydrocarbon extraction samples (5 flies/sample) for each treatment within a group. As the data were not normally distributed, a Kruskal-Wallis rank sum test was used for all three responses, with a separate analysis run for each sex and age for each of the three responses (12 models total). Kruskal-Wallis rank sum tests were performed by using the 'kruskal.test' function in R version 3.5.1 (R Core Team 2015). Wilcoxon rank sum tests were performed for post-hoc analyses by using the 'pairwise.wilcox.test' function in R version 3.5.1, which adjusted $p$-values by using the 'Holm' method (R Core Team 2015).

\section{Experiment 1: Hydrocarbon Regeneration}

\section{Comparison of unsaturated hydrocarbons, aldehydes and saturated hydrocarbons 1, 12, 36, $108 \mathrm{~h}$ after ozonolysis}

We compared the $\mathrm{CHC}$ profiles of ozone treated and untreated 3-5 d and 9-11 d old male and female D. suzukii at 1, 12, 36, 108 h after ozone exposure in 12 separate models (Table 1.). Ozone treatment, $\mathrm{CHC}$ extraction and quantification were performed as described above. A 2 x 4 factorial ANOVA model was used to analyze unsaturated and saturated $\mathrm{CHC}$ concentrations based on experimental treatment (ozone and untreated) and CHC extraction time after treatment (1, 12, 36, $108 \mathrm{~h}$ ) as fixed factors. Aldehyde masses were fit to a linearized model, 'Im' function in R version 3.5.1 prior to ANOVA analysis and, subsequently, a post-hoc Tukey test (R Core Team 2105). ANOVAs and Tukey tests were performed by using the 'aov' and 'TukeyHSD' functions, respectively, in R version 3.5.1 (R Core Team 2015).

\section{Experiment 2: Desiccation Resistance Assessment}

Two desiccation resistance trials were performed on male and female $D$. suzukii (3-5 d). In the first trial, flies were evaluated $1 \mathrm{~h}$ after ozonolysis and in the second, $108 \mathrm{~h}$ after ozonolysis. Methods were modified from Folk et al. (2001). Experimental arenas consisted of 50 $\mathrm{mL}$ polystyrene vials (Lab Express, Cat. \# 8002-cs) containing 4.5 grams of desiccant (W. A. Hammond Drierite Co. Ltd., Stock No: 11001) at their base with a permeable plastic barrier placed above the desiccant. Nine to 11 single sex adult flies were placed into each arena and vials were capped with plastic wrap (Gordon Food Services, Item: 115193). Relative humidity and temperature were measured inside an experimental vial without flies during each trial using an electronic hygrometer sensor (Sensirion, EK-H4). Fly survival was assessed at 30minute intervals for $10 \mathrm{~h}$ or until all flies had died. Fly mortality was determined by lightly shaking a vial and recording the number of individuals that reoriented to a standing position; those who did not re-orient were recorded as dead. As trials were completed when all flies had died, no censored data were included in Kaplan-Meier analyses.

Data for both desiccation trials were also analyzed by Mantel-Haenszel log-rank tests and Cox proportional hazard models with separate analyses performed for male and female flies using the R 'survival' package (Therneau et al. 2020). Trial one compared the survival of male or female $D$. suzukii 1 hour after ozonolysis with flies treated with oxygen or an untreated control. Optimized Cox Proportional Hazard comparisons were made by first evaluating differences between the oxygen and untreated controls; if they were found to be similar, the combined oxygen and untreated controls were compared to the ozone treated flies (Crawley 2007; RICH et al. 2010). Trial two compared the survival of male or female D. suzukii $108 \mathrm{~h}$ after ozonolysis with an untreated control of the same age, so a pairwise comparison of Cox Proportional Hazards was made. Hazard ratios (HR) were determined from Cox Proportional Hazard models. The hazard ratio, or instantaneous rate of death, represents the rate of death in comparison to control survival at any point of time.

\section{Results}

\section{Ozonolysis affects the composition of CHCs on live D. suzukii}

Chromatograms of $D$. suzukii CHCs for untreated controls and ozonated flies show differences $1 \mathrm{~h}$ following ozonolysis but not at $108 \mathrm{~h}$ after ozonolysis (Fig. 2 \& 3). In the former, the total amount of 7-tricosene and other unsaturated hydrocarbons were reduced by approximately half and new aldehyde peaks (heptanal, nonanal, tetradecanal, pentadecanal, hexadecanal, octadecanal) were detected in the ozone treatment (Fig. 2). In the latter, peak heights for 7-tricosene and unsaturated CHC were similar to those observed for the untreated flies, and aldehydes were not observed for either group (Fig. 2). The elution peak positions of the aforementioned compounds and mass chromatograms of the aldehydes are presented in the supplementary data file (Fig. S1).

Experiment 1: Ozonolysis decreases total amount of unsaturated hydrocarbons, producing aldehydes, but do not affect the total amounts of saturated hydrocarbons.

The masses of unsaturated hydrocarbons, aldehydes and saturated hydrocarbons at $1 \mathrm{~h}$ after treatment for 3-5 d and 9-11 $\mathrm{d}$ flies are presented in Table 2. The amounts of unsaturated hydrocarbons of 3-5 d old females were significantly reduced by ozonolysis with $2.03-$ and 1.89 -fold reductions compared to that for the oxygen treated and untreated flies, respectively $\left(\chi^{2}=9.62, d f=2, p=0.0081\right)$, whereas the masses 
were similar between the oxygen treated and untreated flies $(d f=1, p=0.548)$. A similar pattern was observed for 9 -11 $d$ old females with 2.79 and 2.63-fold reductions in ozone treated flies compared to oxygen treated and untreated flies, respectively $\left(\chi^{2}=10.22, d f=2, p=0.006\right)$, and no difference was detected between oxygen and untreated flies ( $d f=1, p=0.222)$. Likewise, 3-5 d old ozone treated males demonstrated 2.85- and 3.10-fold reductions in unsaturated hydrocarbons compared to oxygen treated and untreated 3-5 d old males, respectively $\left(\chi^{2}=11.18\right.$, $d f=2, p=0.0037)$, and similar unsaturated hydrocarbon amount between oxygen and untreated flies $(d f=1, p=0.056)$. Nine-11 $d$ old males presented a slightly different pattern, with 1.63- and 2.28-fold reductions in unsaturated hydrocarbons in ozone treated flies compared to oxygen treated and untreated flies $\left(\chi^{2}=11.52, d f=2, p=0.0031\right)$, and a 1.4 fold reduction in levels observed from the oxygen to the untreated control flies $(d f=1, p=0.032)$.

The masses of aldehydes extracted from 3-5 d old females, 9-11 d old females, 3-5 d old males and 9-11 d old males were significantly increased by ozonolysis compared to oxygen treated and untreated flies $\left(\chi^{2}=13.29, d f=2, p=0.0013, \chi^{2}=13.29, d f=2, p=0.0013, \chi^{2}=13.29\right.$, $d f=2, p=0.0013, \chi^{2}=13.29, d f=2, p=0.0013$, respectively). No aldehydes were extracted from oxygen or untreated flies in 3-5 $d$ old females, $9-11$ $\mathrm{d}$ old females, 3-5 d old males and 9-11 d old males.

The masses of saturated hydrocarbons extracted from 3-5 d old females were significantly increased after ozone treatment compared to oxygen treated and untreated flies $\left(\chi^{2}=9.42, d f=2, p=0.0090\right)$, while the masses were similar between oxygen treated and untreated flies $(d f=1, p=841)$. There was no difference in the masses of saturated hydrocarbons extracted from $9-11 \mathrm{~d}$ old females between ozone treated, oxygen treated and untreated flies $\left(\chi^{2}=1.46, d f=2, p=0.4819\right)$. The masses of saturated hydrocarbons extracted from $3-5 \mathrm{~d}$ old males treated with ozone and oxygen were significantly reduced in comparison to that found in untreated flies $\left(\chi^{2}=8.96, d f=2, p=0.0113\right)$, while saturated hydrocarbon amounts were similar between ozone treated and oxygen treated flies $(d f=1, p=0.548)$. There was no significant difference in the mass of the saturated hydrocarbons extracted from 9-11 d old male untreated flies with those from flies treated with either ozone or oxygen $\left(\chi^{2}=4.58, d f=2, p=0.1013\right)$.

\section{Experiment 1: Hydrocarbons regenerate within 108 hours after ozonolysis}

The masses of unsaturated hydrocarbons, aldehydes and saturated hydrocarbons at 1, 12, 36, $108 \mathrm{~h}$ after treatment for 3-5 d and 9-11 d flies are presented in Table 3 and Figs. 5-7. Statistical output for ANOVA models is presented in Table 4.

Ozone exposure significantly reduced the mass of unsaturated hydrocarbons for male and female flies of both ages at time zero with masses returning to levels comparable to untreated flies within $108 \mathrm{~h}$ (Fig 4). For female flies of both ages, regeneration was comparable to untreated flies within $36 \mathrm{~h}$ with 3-5 day old ozone treated flies producing significantly more unsaturated hydrocarbons than the untreated flies, with mean \pm SEM values of $2145 \pm 79$ and $1489 \pm 112 \mathrm{ng}$, respectively (Figure $5 \mathrm{a}$ ). In contrast, ozone treated male flies of either age did not produce comparable masses of unsaturated hydrocarbons to their respective controls until $108 \mathrm{~h}$ after treatment (Table $4 \mathrm{a}$ ).

Ozone exposure resulted in the formation of aldehydes from both treated sexes at both ages, but virtually no aldehydes were recovered from the untreated flies of either sex or age at any time point (Fig 5). Extractions of ozone treated flies contained aldehydes immediately after treatment with similar patterns of aldehyde reduction over subsequent time periods observed for both sexes and age groups (Table $4 \mathrm{~b}$ ). The aldehyde content approached $0 \mathrm{ng}$ for the 3-5 day and 9-11 day old males and for the 3-5 day old females at $108 \mathrm{~h}$ after exposure. The data for 9-11 day old females at $108 \mathrm{~h}$ after treatment are not presented due to contamination issues. However, the mass of aldehydes for this group was reduced from $715 \pm 28 \mathrm{ng}$ at $1 \mathrm{~h}$ to $90 \pm 6 \mathrm{ng}$ at $36 \mathrm{~h}$ after ozone treatment.

Saturated hydrocarbon measurements provided the least consistent trends across sex and age groups compared to unsaturated hydrocarbons and aldehydes (Table 4c). Significantly higher masses of unsaturated hydrocarbons were detected for ozone treated 3-5 day old females at 1, 12 and $36 \mathrm{~h}$ after treatment (Fig 6a). Likewise, higher masses of unsaturated hydrocarbons were detected for ozone treated 9-11 day old females at 1 and $12 \mathrm{~h}$ with a significant difference detected at $36 \mathrm{~h}$ (Fig. $6 \mathrm{~b}$ ). In contrast, no significant differences between ozone treated and untreated males of either age group were detected at any time point (Fig $6 \mathrm{c}, \mathrm{d}$ ).

\section{Experiment 2: Ozonolysis decreases desiccation resistance in D. suzukii}

Kaplan-Meier survival curves for desiccation trials conducted $1 \mathrm{~h}$ and $108 \mathrm{~h}$ after ozonolysis are presented in Table 5 and Fig. 7. The mean $\left( \pm\right.$ SEM) relative humidity and temperature of desiccation trials at $1 \mathrm{~h}$ after treatment application were $18.13 \%( \pm 1.54 \%)$ and $28.89^{\circ} \mathrm{C}( \pm 0.20)$, respectively. The mean $( \pm$ SEM) relative humidity and temperature of desiccation trials at $108 \mathrm{~h}$ after treatment application were $15.93 \%$ $( \pm 2.12)$ and $28.32^{\circ} \mathrm{C}\left( \pm 0.34^{\circ} \mathrm{C}\right)$, respectively. Optimized Cox Proportional Hazard models for male and female flies $1 \mathrm{~h}$ after ozonolysis compared oxygen and untreated controls to ozone treated flies (Crawley 2007; Rich et al. 2010). Output from Cox Proportional Hazard models for the two trials is presented in Table 6. 
Mantel-Haenszel log-rank tests of female and male survival $1 \mathrm{~h}$ after ozonolysis (trial 1 ) showed significant differences between ozone treated and control flies $\left(c^{2}=158, d f=2, p<0.001, c^{2}=75, d f=2, p<0.001\right.$, respectively). Cox Proportional Hazard models of female and male survival $1 \mathrm{~h}$ after ozonolysis showed significantly reduced survival times of ozone treated flies to the combined control flies $1 \mathrm{~h}$ after ozonolysis ( $z=12.15, d f=1, p<0.001 ; z=8.411, d f=1, p<0.001$, respectively). A Hazard Ratio of 4.267 was observed when comparing controls to ozonated female flies with median times of death of $4.5 \mathrm{~h}$ and $2.5 \mathrm{~h}$, respectively (Table 6). Similarly, ozonated males had a Hazard Ratio of 2.467 when compared to control flies with median times of death of $2 \mathrm{~h}$ and $3 \mathrm{~h}$, respectively (Table 6 ).

Mantel-Haenszel log-rank tests of female and male survival $108 \mathrm{~h}$ after ozonolysis showed significant differences between ozone treated and control flies $\left(c^{2}=4.2, d f=1, p=0.04, c^{2}=22.4, d f=1, p<0.001\right.$, respectively). Cox Proportional Hazard models of female and male survival 108 $\mathrm{h}$ after ozonolysis showed that ozone treated flies had significantly reduced survival times compared to control flies $1 \mathrm{~h}$ after ozonolysis ( $z=-1.972, d f=1, p=0.0486, z=-4.942, d f=1, p<0.001$, respectively). Ozonated females had a Hazard Ratio of 0.753 when compared to control flies with median times of death of $4.5 \mathrm{~h}$ and $4 \mathrm{~h}$, respectively (Table 6). Similarly, ozonated males had a Hazard Ratio of 0.470 when compared to control flies with median times of death of $2.5 \mathrm{~h}$ and $2 \mathrm{~h}$, respectively (Table 6).

\section{Discussion}

Our results demonstrate that ozonolysis of live $D$. suzukii significantly reduces the total amount of unsaturated hydrocarbons, increases of the mass of aldehydes but does not affect the levels of saturated hydrocarbons in hexane extracted CHCs (Fig. 4, 5 \& 6) (Table 3). Furthermore, the levels of $\mathrm{CHCs}$ from flies treated with ozone return to untreated $\mathrm{CHC}$ levels within $108 \mathrm{~h}$ after exposure (Fig. 4, 5 \& 6 and Table 3). However, flies regenerated unsaturated hydrocarbons at different rates depending on their sex and age (Fig. 4 and Table 3). Desiccation resistance was correlated to changes in $\mathrm{CHC}$ abundance, with an immediate decrease followed by recovery over the same time. (Fig. 7 and Table 5). Surprisingly, desiccation resistance significantly increased in comparison to untreated controls at $108 \mathrm{~h}$ after treatment application, although a concomitant significant increase in unsaturated hydrocarbons was only observed for females at $3-5 \mathrm{~d}$ at $36 \mathrm{~h}$ after treatment application (Fig. 4 \& 7 and Table 3 \& 4).

Our study is the first to quantify ozonolysis of $\mathrm{CHCs}$ on living insect specimens and may provide an important new method for exploring the biosynthesis, structure, and function of these important constituents of the insect epicuticle. Current methodology for the modification of living insect $\mathrm{CHCs}$ include genetic modification and direct CHC application via perfuming (Ferveur 1997) (Billeter et al. 2009). While these methodologies are useful for determining the function of $\mathrm{CHCs}$, they are expensive and/or time intensive, requiring the genetic modification of individual species/lineages. Our method could be used to modify the unsaturated hydrocarbons of any insect and allow the measurement of $\mathrm{CHC}$ generation time, potential for regeneration as well as how they modify behavior and survival.

While CHC generation in Drosophila species has been described in previous work (Bartelt et al. 1986; Jallon and David 1987; Toolson and Kuper-Simbron 1989; Dekker et al. 2015; Snellings et al. 2018), ours is a novel study providing data on the regeneration of unsaturated hydrocarbons following their removal from living subjects. The regeneration of $\mathrm{CHCs}$ to untreated levels suggests that maintaining $\mathrm{CHCs}$ is of great importance to $D$. suzkuii. Insect CHCs have been found to function as (1) pheromones, (2) to increase desiccation resistance and (3) to protect from entomo-pathogens (Quinlan and Hadley 1993; Gibbs 1998; Howard and Blomquist 2005; Blomquist and Bagnères 2010; OrtizUrquiza and Keyhani 2013; Chung and Carroll 2015).

Our results also provide evidence that $D$. suzukii of different sexes and ages regenerate $\mathrm{CHCs}$ to untreated levels, albeit point estimates of CHC's vary across these groups (Fig. 4 and Table 3). For example, 3-5 $d$ old and 9-11 d old females regenerated unsaturated hydrocarbons to levels observed in untreated fly by 12 and $36 \mathrm{~h}$ after treatment application, respectively (Fig. 4 and Table 3). However, 3-5 d and 9-11 d males did not regenerate unsaturated hydrocarbons to untreated fly levels until $108 \mathrm{~h}$ after treatment application (Fig. 4 and Table 3). This suggests that females either have a greater capacity to generate $\mathrm{CHCs}$ or prioritize the regeneration of $\mathrm{CHCs}$ after ozonolysis.

Unexpectedly, the mass of saturated hydrocarbons increased over time after ozone exposure in female flies. We propose that the $\mathrm{CHC}$ compensation mechanism for the regeneration of unsaturated hydrocarbons also affects saturated hydrocarbon biosynthesis. One possible explanation may involve the over-expression of a single P450 decarboxylase, Cyp4g1, which is directly involved in the biosynthesis pathway of insect CHCs (Qiu et al. 2012). The over-expression of the P450 decarboxylase would allow the regeneration of unsaturated CHCs to normal levels, as well as the biosynthesis of saturated CHCs to elevated levels (Chung and Carroll 2015).

Insect CHCs have been found to decrease water permeability through the cuticle and, thus increasing desiccation resistance (Quinlan and Hadley 1993; Gibbs 1998; Blomquist and Bagnères 2010; Chung and Carroll 2015). We observed greatly reduced desiccation resistance immediately following ozone treatments with a return to pre-treatment desiccation resistance following the regeneration of unsaturated hydrocarbons (Fig. 4 \& 7. and Table 5). This finding supports the hypothesis that CHCs function to reduce cuticle water permeability (Ramsay 1935; Gibbs 1998) and that D. suzukii unsaturated hydrocarbons play a significant role in their desiccation resistance. This is of interest 
because it has been previously suggested that saturated hydrocarbons are generally more correlated with desiccation resistance due to their higher melting points (Gibbs and Pomonis 1995). Additional supporting evidence suggests that a greater abundance of long-chained saturated hydrocarbons impart greater desiccation resistance by reducing the water loss rate (WLR) in D. pseudoobscura and Tibicen dealbatus (Homoptera: Cicadidae) (Toolson 1984; Toolson and Kuper-Simbron 1989).

Our data provide strong correlative evidence for the importance of unsaturated CHC's for desiccation resistance in D. suzukii. Gibbs (2002) hypothesizes that alkenes and alkanes form layers on the epicuticle dependently on lipid melting points. Alkenes may form liquid layers on the cuticle and allow greater permeability of water due to their lower melting temperatures (Gibbs 2002). This layered packing of alkanes and alkenes could help to explain the decreased survival rate of ozone treated flies as well as the uniform reduction of all unsaturated hydrocarbons. Furthermore, SEM images of a tick cuticle, Rhipicephalus sanguineus (Latreille) (Ixodida: Ixodidae), after ozone exposure qualitatively shows the damaging impact of ozone to the epicuticle layer (Moreira et al. 2018). This provides additional evidence to support the correlation of decreased desiccation resistance resulting from ozone mediated damage to the epicuticle.

While our data strongly suggest that desiccation resistance is directly linked to unsaturated hydrocarbon quantity, it is possible that observed differences were due to other ozone induced effects. The ozonolysis performed in this experiment, while largely non-lethal, did result in some mortality. Dose response curves developed in Savage (2020) predict that a CT product of 3,750 ppm-min of gaseous ozone would result in $11 \%$ and $25 \%$ mortality immediately following ozonolysis for males and females, respectively (Savage 2020). One potential, non-desiccation, source of mortality could be tracheal damage resulting from ozone exposure. However, Sousa et al. (2008) examined the respiration rates of T. castaneum, $R$. dominica and $O$. surinamensis and concluded that ozone toxicity and respiration rates did not correlate (Sousa et al. 2008). Our study did not directly measure the respiration rate of specimens after ozone exposure.

Potential future applications of ozonolysis of CHCs include characterizing arthropod physiology and behavior in regards to desiccation, chemical communication and entomopathogen resistance (Quinlan and Hadley 1993; Gibbs 1998; Howard and Blomquist 2005; Blomquist and Bagnères 2010; Ortiz-Urquiza and Keyhani 2013; Chung and Carroll 2015). Unsaturated hydrocarbons have been shown to be important in Drosophila spp. for identification of conspecifics and courtship/mating behaviors (Antony et al. 1985; Jallon and David 1987; Ferveur 1997, 2005; Howard and Blomquist 2005). For example, 7,11-heptacosadiene has been shown to be an aphrodisiac for male D. melanogaster (Antony et al. 1985). Cleavage of the double bonds of 7,11-heptacosadiene at the $7^{\text {th }}$ and $11^{\text {th }}$ carbon positions would occur after an ozone treatment using our methodology. This method could be combined with mating assays to determine how courtship and copulation are affected after ozonolysis of unsaturated hydrocarbons.

Ozonolysis of CHCs could also be combined with genetic modification of CHCs or CHC perfuming (Ferveur 1997, 2005). For example, ozonolysis of the genetically modified oenocyte-less (oe-) fly lineage of D. melanogaster, that produces no CHCs (Billeter et al. 2009) could be used to further elucidate whether ozonolysis effects desiccation resistance in the absence of CHCs. Additionally, courtship and copulation is shown to be mediated by unsaturated hydrocarbons, such as the anti-aphrodisiac 7-tricosene, in both D. suzukii flies and D. melanogaster males (Ferveur 1997; Snellings et al. 2018). Post ozonolysis "perfuming" of insects could be used to evaluate the relative importance of specific semiochemicals in courtship and mate selection. Ozonolysis of unsaturated hydrocarbons on female D. suzukii were correlated to reduced courtship and/or copulation by untreated males (unpublished data). This is counter-intuitive to the reduction of the 7-tricosene (an anti-aphrodisiac) after ozonolysis but may be explained by the interaction of ozone with other insect tissues. For example, dominant lethal chemicals have been shown to be produced after ozone exposure, which cause mutagenicity and a reduced reproductive potential in $D$. virilis (Erdman and Hernandez 1982).

In conclusion, the masses of $D$. suzukii unsaturated hydrocarbons are significantly reduced by a factor of 2-3 after ozone treatment due to the process of ozonolysis. This creates aldehydes which remain on the cuticle for between 36 and $108 \mathrm{~h}$. The saturated $\mathrm{CHC}$ amount on flies are largely unaffected by ozone treatment, except for female flies at 3-5 d where a significant increase in saturated hydrocarbons were found. Additionally, flies demonstrated differential $\mathrm{CHC}$ regeneration based on sex and age. Females regenerated $\mathrm{CHCs}$ more quickly than males, as well as having an increased $\mathrm{CHC}$ regeneration rate at 3-5 d than 9-11 d. Finally, the reduction and recovery of desiccation resistance in ozone treated flies was correlated to the reduction and regeneration of unsaturated hydrocarbons. However, the desiccation resistance of ozone treated flies was elevated above untreated flies after unsaturated $\mathrm{CHC}$ regeneration. These findings provide novel methodology for insect $\mathrm{CHC}$ reduction/modification, evidence for $\mathrm{CHC}$ regeneration after reduction/modification and evidence supporting the contribution of unsaturated hydrocarbons in desiccation resistance.

\section{Declarations}

Funding: Organic Pest Management lab of the Entomology Department at Michigan State University.

Conflicts of interest/Competing interests: NA

Page $7 / 22$ 
Availability of data and material: Available upon request.

Code availability: Available upon request.

Authors' contributions:

- Benjamin Savage designed experiments, executed experiments, collected data, performed statistical analysis, wrote code for statistical analysis, developed figures and wrote the article.

- Zinan Wang provided methodological support for cuticular extractions, GC/MS set-up, and developed figures.

- Susan Masten provided ozone concentration measurement equipment and scientific advice

- Henry Chung provided experimental design support.

- Matthew Grieshop provided scientific leadership, equipment, and funding.

\section{References}

1. Antony C, Davis TL, Carlson DA, et al (1985) Compared behavioral responses of maleDrosophila melanogaster (Canton S) to natural and synthetic aphrodisiacs. J Chem Ecol 11:1617-1629. https://doi.org/10.1007/BF01012116

2. Bartelt RJ, Armold MT, Schaner AM, Jackson LL (1986) Comparative analysis of cuticular hydrocarbons in the Drosophila virilis species group. Comp Biochem Physiol Part B Comp Biochem 83:731-742. https://doi.org/10.1016/0305-0491(86)90138-0

3. Bartelt RJ, Jones RL, Kulman HM (1982) Hydrocarbon components of the yellowheaded spruce sawfly sex pheromone. J Chem Ecol 8:95-114. https://doi.org/10.1007/BF00984008

4. Beroza Morton, Bierl BA (1967) Rapid determination of olefin position in organic compounds in microgram range by ozonolysis and gas chromatography. Alkylidene analysis. Anal Chem 39:1131-1135. https://doi.org/10.1021/ac60254a038

5. Billeter J-C, Atallah J, Krupp JJ, et al (2009) Specialized cells tag sexual and species identity in Drosophila melanogaster. Nature 461:987-991. https://doi.org/10.1038/nature08495

6. Blomquist GJ, Bagnères A-G (2010) Insect Hydrocarbons: Biology, Biochemistry, and Chemical Ecology. Cambridge University Press

7. Bolda MP, Goodhue RE, Zalom FG (2010) Spotted Wing Drosophila: Potential Economic Impact of a Newly Established Pest. 4

8. Chung H, Carroll SB (2015) Wax, sex and the origin of species: Dual roles of insect cuticular hydrocarbons in adaptation and mating. BioEssays 37:822-830. https://doi.org/10.1002/bies.201500014

9. Crawley MJ (2007) The R Book. John Wiley \& Sons

10. Dalton DT, Walton VM, Shearer PW, et al (2011) Laboratory survival of Drosophila suzukii under simulated winter conditions of the Pacific Northwest and seasonal field trapping in five primary regions of small and stone fruit production in the United States. Pest Manag Sci 67:1368-1374. https://doi.org/10.1002/ps.2280

11. Dekker T, Revadi S, Mansourian S, et al (2015) Loss of Drosophila pheromone reverses its role in sexual communication in Drosophila suzukii. Proc R Soc B Biol Sci 282:. https://doi.org/10.1098/rspb.2014.3018

12. Erdman HE, Hernandez T (1982) Adult toxicity and dominant lethals induced by ozone at specific stages in spermatogenesis in drosophila virilis. Environ Mutagen 4:657-666. https://doi.org/10.1002/em.2860040605

13. Ferveur J-F (1997) The pheromonal role of cuticular hydrocarbons in Drosophila melanogaster. BioEssays 19:353-358. https://doi.org/10.1002/bies.950190413

14. Ferveur J-F (2005) Cuticular Hydrocarbons: Their Evolution and Rolesin Drosophila Pheromonal Communication. Behav Genet 35:279. https://doi.org/10.1007/s10519-005-3220-5

15. Gibbs A, Pomonis JG (1995) Physical properties of insect cuticular hydrocarbons: The effects of chain length, methyl-branching and unsaturation. Comp Biochem Physiol B Biochem Mol Biol 112:243-249. https://doi.org/10.1016/0305-0491(95)00081-X

16. Gibbs AG (1998) Water-Proofing Properties of Cuticular Lipids. Integr Comp Biol 38:471-482. https://doi.org/10.1093/icb/38.3.471

17. Gibbs AG (2002) Lipid melting and cuticular permeability: new insights into an old problem. J Insect Physiol 48:391-400. https://doi.org/10.1016/S0022-1910(02)00059-8

18. Hadley NF (1994) Ventilatory Patterns and Respiratory Transpiration in Adult Terrestrial Insects. Physiol Zool 67:175-189. https://doi.org/10.1086/physzool.67.1.30163841 
19. Howard RW, Blomquist GJ (2005) Ecological, Behavioral, and Biochemical Aspects of Insect Hydrocarbons. Annu Rev Entomol 50:371393. https://doi.org/10.1146/annurev.ento.50.071803.130359

20. Howard RW, Jackson LL, Banse H, Blows MW (2003) Cuticular Hydrocarbons of Drosophila birchii and D. serrata: Identification and Role in Mate Choice in D. serrata. J Chem Ecol 29:961-976. https://doi.org/10.1023/A:1022992002239

21. Jallon J-M, David JR (1987) Variation in Cuticular Hydrocarbons Among the Eight Species of the Drosophila melanogaster Subgroup. Evolution 41:294-302. https://doi.org/10.2307/2409139

22. Moreira LH, Figueiredo TFB, Alves LP, et al (2018) Effect of Ozone as Acaricide: Action of the Ozone on the Cuticle and Respiratory Spiracle of Tick Rhipicephalus sanguineus sensu lato. Ozone Sci Eng 40:183-190. https://doi.org/10.1080/01919512.2017.1403306

23. Ortiz-Urquiza A, Keyhani NO (2013) Action on the Surface: Entomopathogenic Fungi versus the Insect Cuticle. Insects 4:357-374. https://doi.org/10.3390/insects4030357

24. Qiu Y, Tittiger C, Wicker-Thomas C, et al (2012) An insect-specific P450 oxidative decarbonylase for cuticular hydrocarbon biosynthesis. Proc Natl Acad Sci 109:14858-14863. https://doi.org/10.1073/pnas.1208650109

25. Quinlan MC, Hadley NF (1993) Gas Exchange, Ventilatory Patterns, and Water Loss in Two Lubber Grasshoppers: Quantifying Cuticular and Respiratory Transpiration. Physiol Zool 66:628-642. https://doi.org/10.1086/physzool.66.4.30163812

26. R Core Team (2015) R: A language and environment for statistical computing. R Foundation for Statistical Computing. Vienna, Autria

27. Ramsay JA (1935) The Evaporation of Water from the Cockroach. J Exp Biol 12:373-383

28. Rich JT, Neely JG, Paniello RC, et al (2010) A Practical Guide To Understanding Kaplan-Meier Curves. Otolaryngol-Head Neck Surg Off J Am Acad Otolaryngol-Head Neck Surg 143:331-336. https://doi.org/10.1016/j.otohns.2010.05.007

29. Savage BA (2020) Exploring The Insecticidal Potential Of Aqueous And Gaseous Ozone Using Spotted Wing Drosophila, Drosophila suzukii (Matsumura) (Diptera-drosophilidae) As A Model Organism. Michigan State University

30. Snellings Y, Herrera B, Wildemann B, et al (2018) The role of cuticular hydrocarbons in mate recognition in Drosophila suzukii. Sci Rep 8:4996. https://doi.org/10.1038/s41598-018-23189-6

31. Sousa AH, Faroni LRD, Guedes RNC, et al (2008) Ozone as a management alternative against phosphine-resistant insect pests of stored products. J Stored Prod Res 44:379-385. https://doi.org/10.1016/j.jspr.2008.06.003

32. Toolson EC (1984) Interindividual Variation in Epicuticular Hydrocarbon Composition and Water Loss Rates of the Cicada Tibicen dealbatus (Homoptera: $\quad$ Cicadidae). Physiol Zool 57:550-556. https://doi.org/10.1086/physzool.57.5.30163947

33. Toolson EC, Kuper-Simbron R (1989) Laboratory Evolution of Epicuticular Hydrocarbon Composition and Cuticular Permeability in Drosophila pseudoobscura: Effects on Sexual Dimorphism and Thermal-Acclimation Ability. Evolution 43:468-473. https://doi.org/10.2307/2409222

34. Waters (2020) MassLynx MS Software. In: Waters. https://www.waters.com/waters/en_US/MassLynx-MS-Software/nav.htm? cid=513662\&locale=en_US. Accessed 1 Apr 2020

\section{Tables}

Table 1 Experiment 1, 2 \& 3 data collection times, treatments, fly age and replication. An '*' in the 'Replication (Male, Female)' column indicates the same number of replications at every data collection time in the 'Data Collection Hour after Treatment Application' column and a ';' indicates a separation of replication numbers consistent with the data collection times in the 'Data Collection Time after Treatment Application $(\mathrm{h}(\mathrm{s}))^{\prime}$ column. 


\begin{tabular}{|c|c|c|c|c|}
\hline \multicolumn{5}{|c|}{ EXPERIMENT SET-UP } \\
\hline Experiment & $\begin{array}{l}\text { CHC Extraction Hour after Treatment } \\
\text { Application }\end{array}$ & Treatment & $\begin{array}{l}\text { Fly Age (days) at Treatment } \\
\text { application }\end{array}$ & $\begin{array}{l}\text { Replication } \\
\text { Female) }\end{array}$ \\
\hline \multirow{6}{*}{$\begin{array}{l}\text { Experiment } \\
1\end{array}$} & 1 & Oxygen & $3-5$ & 25,25 \\
\hline & $1,12,36,108$ & Untreated & $3-5$ & $\star 25,25$ \\
\hline & $1,12,36,108$ & Ozone & $3-5$ & $\star 25,25$ \\
\hline & 1 & Oxygen & $9-11$ & 25,25 \\
\hline & $1,12,36$ & Untreated & $9-11$ & $\star 25,25$ \\
\hline & $1,12,36$ & Ozone & $9-11$ & $\star 25,25$ \\
\hline \multirow{3}{*}{$\begin{array}{l}\text { Experiment } \\
2\end{array}$} & 1 & Oxygen & $3-5$ & 140,141 \\
\hline & 1,108 & Untreated & $3-5$ & 138,$140 ; 100,99$ \\
\hline & 1,108 & Ozone & $3-5$ & 141,$140 ; 101,99$ \\
\hline
\end{tabular}

Table 2 Mean (ng) and standard error of mean (SEM) of unsaturated hydrocarbons, aldehydes and saturated hydrocarbons extracted from female and male flies at $1 \mathrm{~h}$ after treatment application (3-5 \& 9-11 days old). Disparate letters signify differences within a population-based Wilcoxon rank sum test with Holm p-adjustment. 


\begin{tabular}{|c|c|c|c|c|c|c|}
\hline \multicolumn{7}{|c|}{ CUTICULAR COMPOUND MASS (NG) OF D. SUZUKII AT 1 H AFTER TREATMENT } \\
\hline \multicolumn{7}{|c|}{ Unsaturated hydrocarbons } \\
\hline \multicolumn{7}{|l|}{ Females } \\
\hline & $3-5 d$ & & & $9-11 d$ & & \\
\hline Treatment & Mean & SEM & CLD & Mean & SEM & CLD \\
\hline Ozone & 721 & 52 & $b$ & 1017 & 85 & $b$ \\
\hline Oxygen & 1462 & 101 & $\mathrm{a}$ & 2832 & 78 & a \\
\hline Untreated & 1366 & 45 & $a$ & 2664 & 108 & $\mathrm{a}$ \\
\hline \multicolumn{7}{|l|}{ Males } \\
\hline & $3-5 d$ & & & $9-11 d$ & & \\
\hline & Mean & SEM & CLD & Mean & SEM & CLD \\
\hline Ozone & 586 & 5 & $b$ & 894 & 110 & c \\
\hline Oxygen & 1674 & 32 & a & 1453 & 132 & $b$ \\
\hline Untreated & 1817 & 76 & a & 2036 & 64 & a \\
\hline \multicolumn{7}{|l|}{ Aldehydes } \\
\hline \multicolumn{7}{|l|}{ Females } \\
\hline & $3-5 d$ & & & $9-11 d$ & & \\
\hline Treatment & Mean & SEM & CLD & Mean & SEM & CLD \\
\hline Ozone & 574 & 18 & a & 715 & 28 & a \\
\hline Oxygen & 0 & 0 & $b$ & 0 & 0 & $b$ \\
\hline Untreated & 0 & 0 & $b$ & 0 & 0 & $b$ \\
\hline \multicolumn{7}{|l|}{ Males } \\
\hline & $3-5 d$ & & & $9-11 d$ & & \\
\hline & Mean & SEM & CLD & Mean & SEM & CLD \\
\hline Ozone & 382 & 11 & a & 443 & 32 & a \\
\hline Oxygen & 0 & 0 & $b$ & 0 & 0 & $b$ \\
\hline Untreated & 0 & 0 & $b$ & 0 & 0 & $b$ \\
\hline \multicolumn{7}{|c|}{ Saturated hydrocarbons } \\
\hline \multicolumn{7}{|l|}{ Females } \\
\hline & $3-5 d$ & & & $9-11 d$ & & \\
\hline Treatment & Mean & SEM & CLD & Mean & SEM & CLD \\
\hline Ozone & 495 & 12 & a & 716 & 45 & a \\
\hline Oxygen & 333 & 24 & $b$ & 668 & 35 & a \\
\hline Untreated & 319 & 9 & $b$ & 648 & 32 & a \\
\hline \multicolumn{7}{|l|}{ Males } \\
\hline & $3-5 d$ & & & $9-11 d$ & & \\
\hline & Mean & SEM & CLD & Mean & SEM & CLD \\
\hline
\end{tabular}

Page $11 / 22$ 


\begin{tabular}{|lllllll|} 
Ozone & 344 & 7 & $\mathrm{a}$ & 503 & 37 & $\mathrm{a}$ \\
\hline Oxygen & 350 & 10 & $\mathrm{a}$ & 378 & 38 & $\mathrm{a}$ \\
\hline Untreated & 397 & 18 & $\mathrm{~b}$ & 485 & 20 & $\mathrm{a}$ \\
\hline
\end{tabular}

Table 3 Unsaturated hydrocarbons, aldehydes and saturated hydrocarbons mean amount extracted from flies (3-5 \& 9-11 days old). Cuticular hydrocarbon extractions occurred at $1 \mathrm{~h}, 12 \mathrm{~h}, 36 \mathrm{~h}$ and $108 \mathrm{~h}$ after treatment application. CLD marks differences between "Treatment Hours" means based on an ANOVA p-values. Disparate letters only signify differences within a sex and age. 


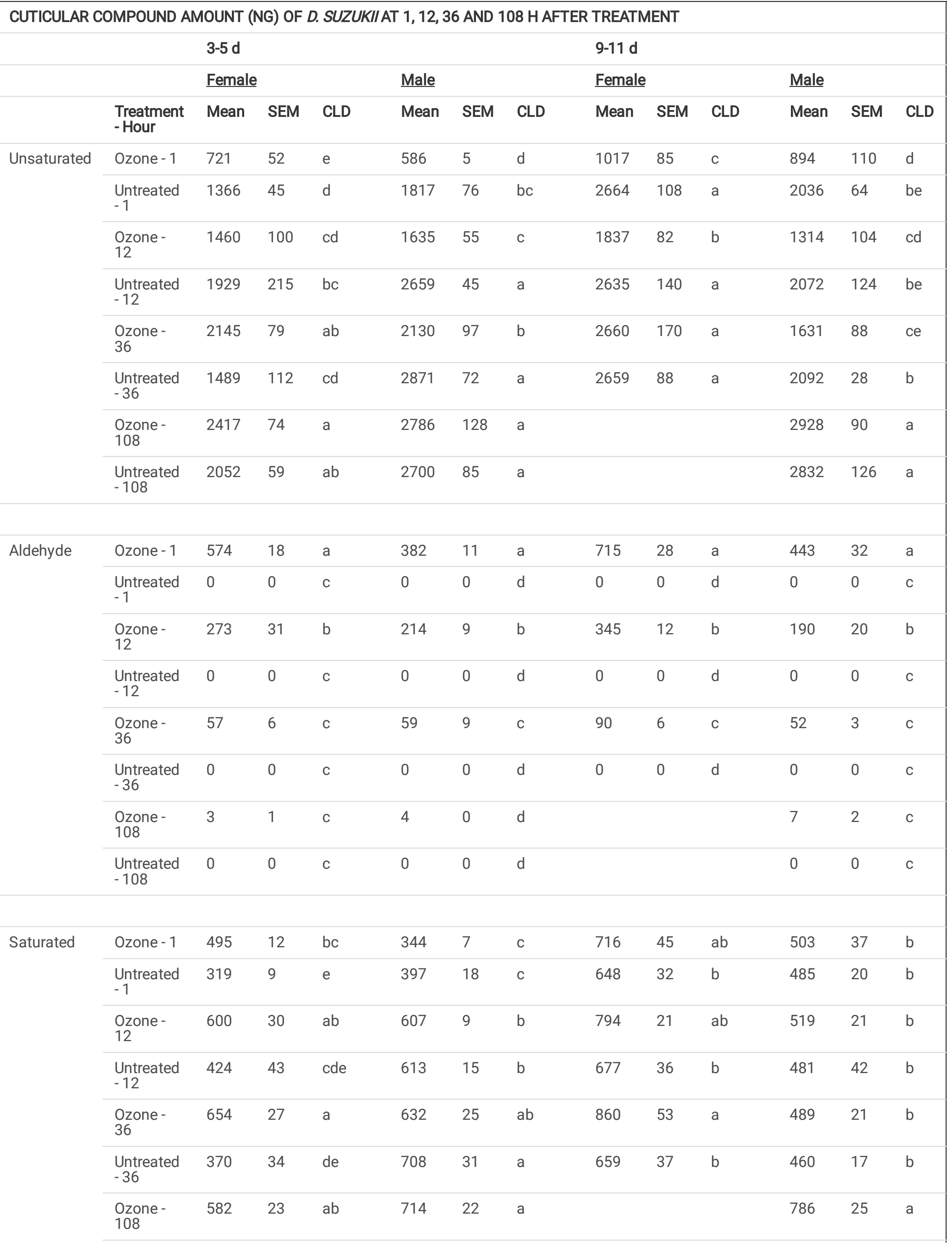


Table 4 Results of $2 \times 4$ factorial ANOVA models comparing treatment to $\mathrm{CHC}$ extraction time after treatment $(1,12,36$ and $108 \mathrm{~h})$ on

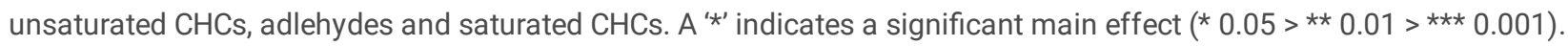




\begin{tabular}{|c|c|c|c|c|c|c|}
\hline \multicolumn{7}{|c|}{ ANOVA MODELS COMPARING CHC MASS (NG) OF D. SUZUKII OVERTIME } \\
\hline \multicolumn{7}{|c|}{ Unsaturated hydrocarbons } \\
\hline \multicolumn{7}{|l|}{ Females } \\
\hline a). & \multicolumn{3}{|c|}{$3-5 d$} & \multicolumn{3}{|c|}{$9-11 d$} \\
\hline Factors & $d f$ & $F$ & $p$ & $d f$ & $F$ & $p$ \\
\hline Treatment & 1 & 0.094 & 0.761 & 1 & 73.1 & $* * *<0.001$ \\
\hline Hour & 3 & 43.8 & $\star \star \star * 0.001$ & 2 & 24.6 & $\star \star \star<0.001$ \\
\hline Treatment:Hour & 3 & 18 & $\star \star \star * 0.001$ & 2 & 24.9 & $\star \star \star<0.001$ \\
\hline \multicolumn{7}{|l|}{ Males } \\
\hline & \multicolumn{3}{|c|}{$3-5 d$} & \multicolumn{3}{|c|}{$9-11 d$} \\
\hline & $d f$ & $F$ & $p$ & $d f$ & $F$ & $p$ \\
\hline Treatment & 1 & 173 & $\star \star *<0.001$ & 1 & 68.5 & $* * *<0.001$ \\
\hline Hour & 3 & 150 & $\star \star \star \star<0.001$ & 3 & 83.4 & $\star \star \star<0.001$ \\
\hline Treatment:Hour & 3 & 27.4 & $\star * *<0.001$ & 3 & 14.5 & $\star * \star<0.001$ \\
\hline \multicolumn{7}{|l|}{ Aldehydes } \\
\hline \multicolumn{7}{|l|}{ Females } \\
\hline b). & \multicolumn{3}{|c|}{$3-5 d$} & \multicolumn{3}{|c|}{$9-11 d$} \\
\hline Factors & $d f$ & $F$ & $p$ & $d f$ & $F$ & $p$ \\
\hline Treatment & 1 & 618 & $\star * *<0.001$ & 1 & 1320 & $\star \star \star * 0.001$ \\
\hline Hour & 3 & 201 & $\star \star \star \star<0.001$ & 2 & 297 & $* \star *<0.001$ \\
\hline Treatment:Hour & 3 & 201 & $\star \star \star \star ~<0.001$ & 2 & 297 & $\star \star \star * 0.001$ \\
\hline \multicolumn{7}{|l|}{ Males } \\
\hline & \multicolumn{3}{|c|}{$3-5 d$} & \multicolumn{3}{|c|}{ 9-11d } \\
\hline c) & $d f$ & $F$ & $p$ & $d f$ & $F$ & $p$ \\
\hline Treatment & 1 & 1492. & $\star \star \star * 0.001$ & 1 & 340.8 & $\star * *<0.001$ \\
\hline Hour & 3 & 396.9 & $\star \star \star * 0.001$ & 3 & 109.5 & $* \star *<0.001$ \\
\hline Treatment:Hour & 3 & 396.9 & $\star \star \star * 0.001$ & 3 & 109.5 & $\star \star \star * 0.001$ \\
\hline \multicolumn{7}{|c|}{ Saturated hydrocarbons } \\
\hline \multicolumn{7}{|l|}{ Females } \\
\hline & \multicolumn{3}{|c|}{$3-5 d$} & \multicolumn{3}{|c|}{$9-11 d$} \\
\hline Factors & $d f$ & $F$ & $p$ & $d f$ & $F$ & $p$ \\
\hline Treatment & 1 & 93.4 & $\star \star * * 0.001$ & 1 & 16.6 & $\star * *<0.001$ \\
\hline Hour & 3 & 8.87 & $\star \star \star<0.001$ & 2 & 2.12 & 0.143 \\
\hline Treatment:Hour & 3 & 4 & * 0.016 & 2 & 1.50 & 0.243 \\
\hline \multicolumn{7}{|l|}{ Males } \\
\hline & \multicolumn{3}{|c|}{$3-5 d$} & \multicolumn{3}{|c|}{$9-11 d$} \\
\hline & $d f$ & $F$ & $p$ & $d f$ & $F$ & $p$ \\
\hline
\end{tabular}




\begin{tabular}{|c|c|c|c|c|c|c|}
\hline Treatment & 1 & 3.98 & 0.055 . & 1 & 4.04 & 0.053 \\
\hline Hour & 3 & 111 & $\star \star \star * 0.001$ & 3 & 43.3 & $\star \star \star * 0.001$ \\
\hline Treatment:Hour & 3 & 2.30 & 0.096 . & 3 & 0.383 & 0.766 \\
\hline
\end{tabular}

Table 5 Kaplan-Meier survival analyses of desiccation resistance from flies (3-5 days old). Flies (10) were placed into a plastic vial with a desiccant, drierite, and sealed. Flies were consider living until they failed to re-orient to a standing position after a shake of the vial. Flies that did not re-orient were marked as deceased. No censored data were included in the analyses.

\begin{tabular}{|c|c|c|c|c|c|}
\hline \multicolumn{6}{|c|}{ KAPLAN-MEIER SURVIVAL ANALYSIS } \\
\hline Sex & Time (h) & Treatment & Sample Size & $\tilde{\mathbf{x}}$ & $95 \% \mathrm{CL}$ \\
\hline & & & & (Median h) & (Lower-Upper) \\
\hline \multirow[t]{6}{*}{ Female } & \multirow[t]{4}{*}{1} & Untreated & 141 & 5 & $4.5-5.5$ \\
\hline & & Oxygen & 140 & 4 & $4-5$ \\
\hline & & Ozone & 140 & 2.5 & $2.5-5$ \\
\hline & & Untreated/Oxygen & 281 & 4.5 & $4.5-5$ \\
\hline & \multirow[t]{2}{*}{108} & Untreated & 99 & 4 & $3.5-4$ \\
\hline & & Ozone & 99 & 4.5 & $4-5$ \\
\hline \multirow[t]{6}{*}{ Male } & \multirow[t]{4}{*}{1} & Untreated & 140 & 3 & $3-3.5$ \\
\hline & & Oxygen & 138 & 3 & $2.5-3.5$ \\
\hline & & Ozone & 141 & 2 & $2-2$ \\
\hline & & Untreated/Oxygen & 278 & 3 & 3-3.5 \\
\hline & \multirow[t]{2}{*}{108} & Untreated & 100 & 2 & $2-2.5$ \\
\hline & & Ozone & 101 & 2.5 & $2.5-3$ \\
\hline
\end{tabular}

Table 6 Cox proportional hazard analysis models performed on fly survival within a sex and $\mathrm{h}$ after treatment application. All model parameters compared to untreated fly survival within the same sex and $h$. The ' $\beta$ ' is the parameter estimate. The 'SE' is the standard error of the ' $\beta$ '. The 'HR' is the hazard ratio. The 'CL' is the confidence level.

\begin{tabular}{|c|c|c|c|c|c|c|c|c|c|}
\hline \multicolumn{10}{|c|}{ SURVIVAL MODELS: COX PROPORTIONAL HAZARD REGRESSION ANALYSIS } \\
\hline & & Parameters & $\boldsymbol{\beta}$ & SE & $d f$ & $z$ & $P$ & $H R$ & 95\% CL (Lower-Upper) \\
\hline Sex & $H(s)$ & Baseline:Comparison & & & & & & & \\
\hline \multirow[t]{2}{*}{ Female } & 1 & Untreated+Oxygen:Ozone & 1.451 & 0.119 & 1 & 12.150 & $<0.001$ & 4.267 & $3.377-5.392$ \\
\hline & 108 & Untreated:Ozone & -0.284 & 0.144 & 1 & -1.972 & 0.049 & 0.753 & $0.567-0.998$ \\
\hline \multirow[t]{2}{*}{ Male } & 1 & Untreated+Oxygen:Ozone & 0.903 & 0.107 & 1 & 8.411 & $<0.001$ & 2.467 & $1.999-3.045$ \\
\hline & 108 & Untreated:Ozone & -0.756 & 0.153 & 1 & -4.942 & $<0.001$ & 0.470 & $0.348-0.634$ \\
\hline
\end{tabular}




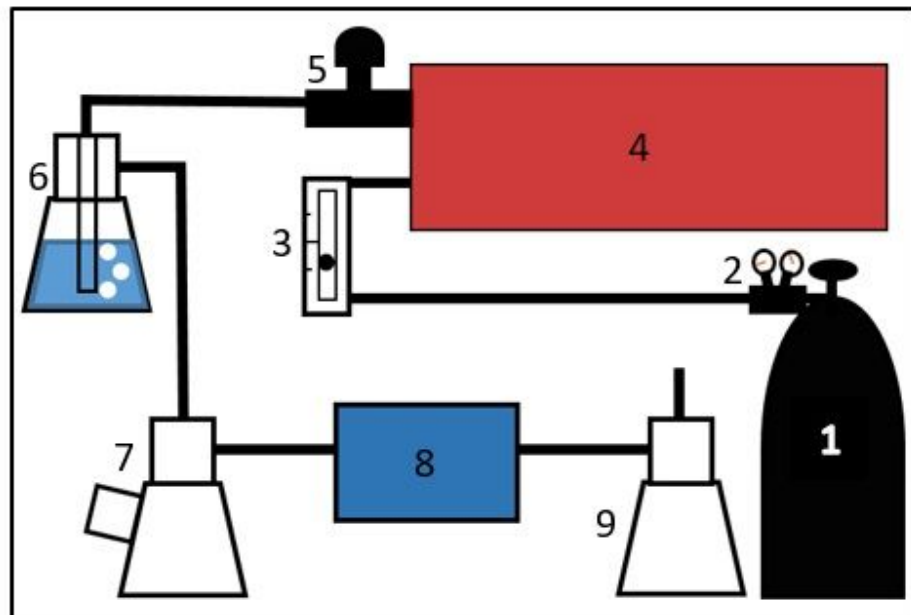

Figure 1. - Gaseous Ozone Experiment Setup

1. Oxygen Tank (99.5\%)

2. Pressure Gauge

3. Airflow Meter

4. Nano Ozone Generator ${ }^{\mathrm{TM}}$ (Absolute Ozone)

5. Needle Valve

6. Bubbler - Flask $(250 \mathrm{~mL})$

7. Gas Washing Flask $(250 \mathrm{~mL})$

8. Ozone Monitor - 106- $\mathrm{H}^{\mathrm{TM}}$ (2B Technologies)

9. Flask $(250 \mathrm{~mL})$ - Relative Humidity Samples

*All parts in contact with ozone are under fume hood for safety

Figure 1

Ozone generation and treatment arena set-up 


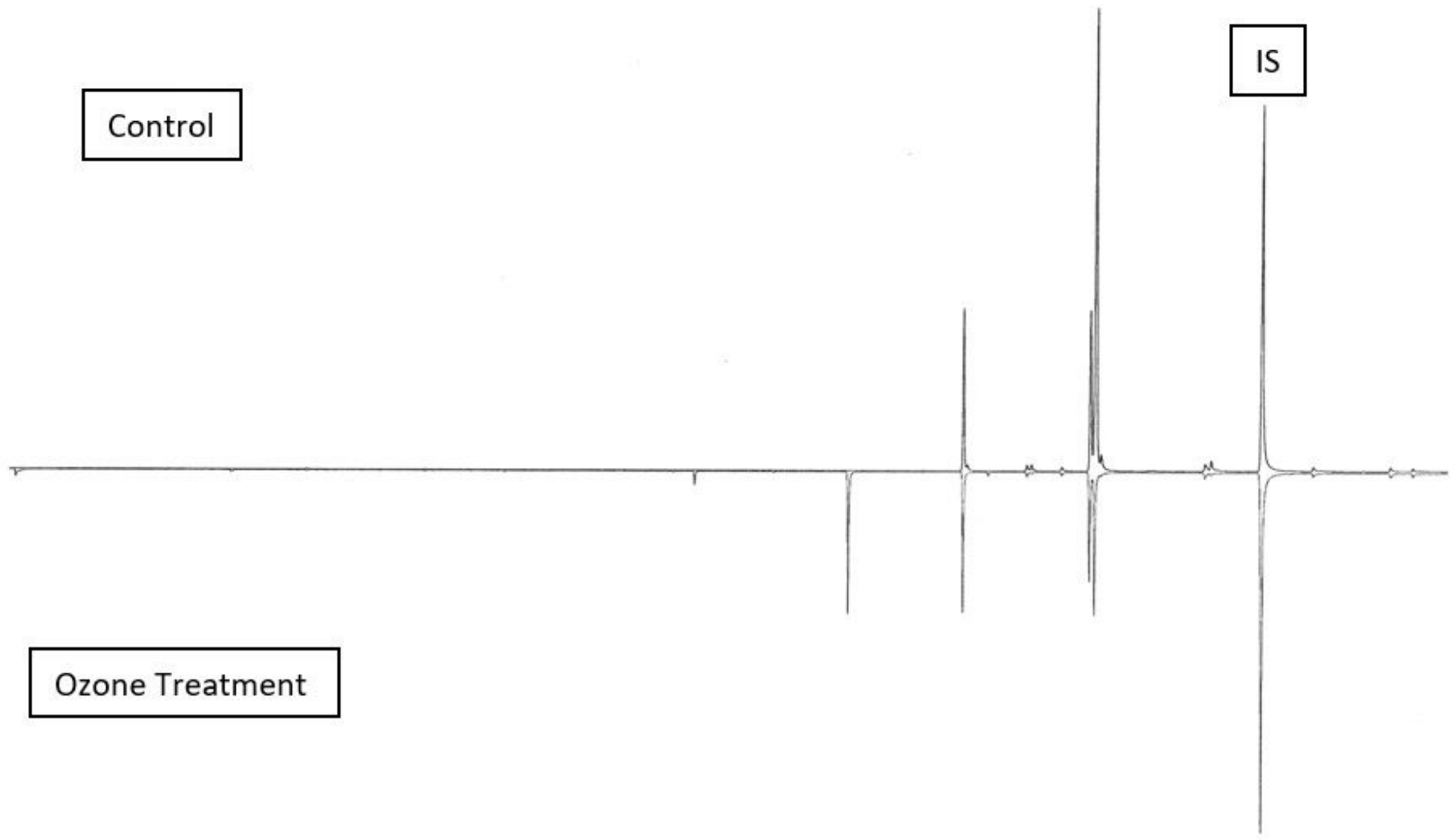

Figure 2

Comparison of a gas chromatogram of a control fly (top) versus an ozone fly (bottom) cuticular hydrocarbon profile at $1 \mathrm{~h}$ after ozonolysis. Hexacosane $(25 \mathrm{ng} / \mu \mathrm{L})$ was used as an internal standard (IS).

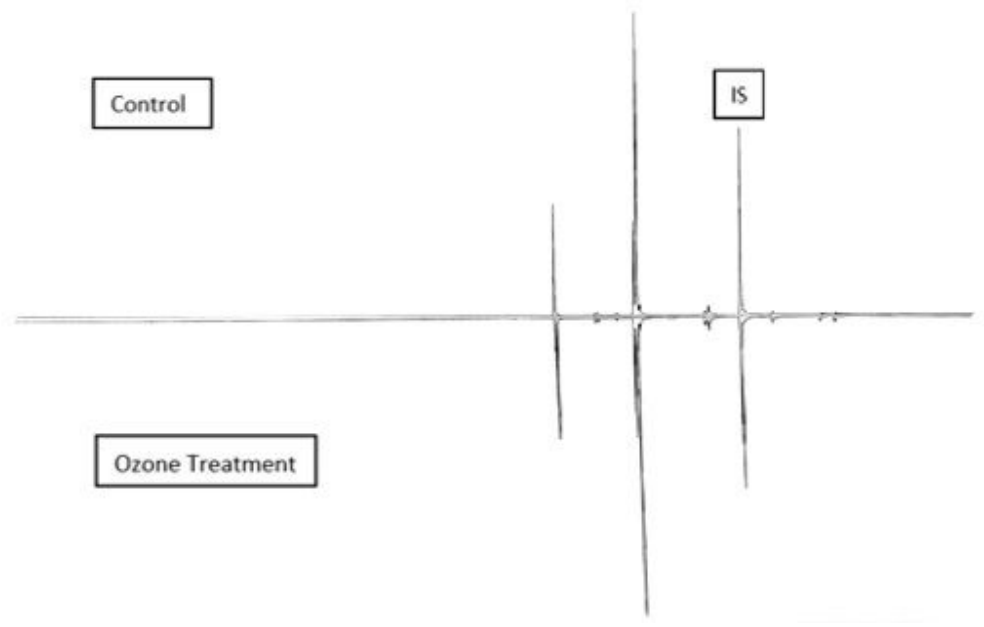

\section{Figure 3}

Comparison of a gas chromatogram of a control fly (top) versus an ozone fly (bottom) cuticular hydrocarbon profile at $108 \mathrm{~h}$ after ozonolysis. Hexacosane $(25 \mathrm{ng} / \mu \mathrm{L})$ was used as an internal standard (IS). 
Mean Amount (ng) of Unsaturated CHCs ((5)C23, (7)C23, (9)C23/C23, (5)C25, (7)C25, (9)C25)
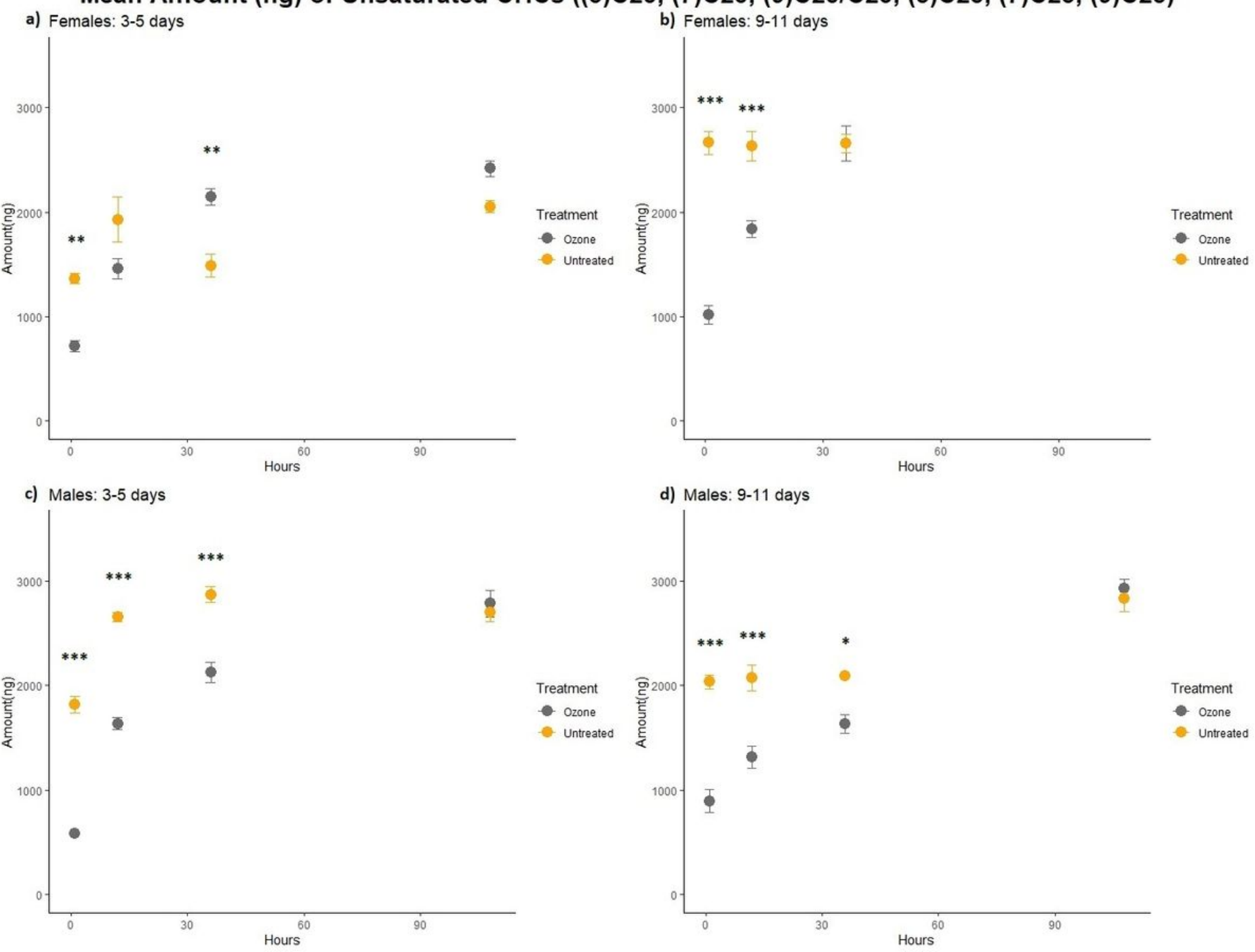

Figure 4

Graphs separated by fly age (3-5 d, 9-11 d). Samples were collected at 1, 12, 36 \& $108 \mathrm{~h}$ after treatment. A significant difference between ozone treated and untreated flies within a $\mathrm{CHC}$ extraction hour are marked with a '*' (*:0.05, **:0.01, ***:0.001). 


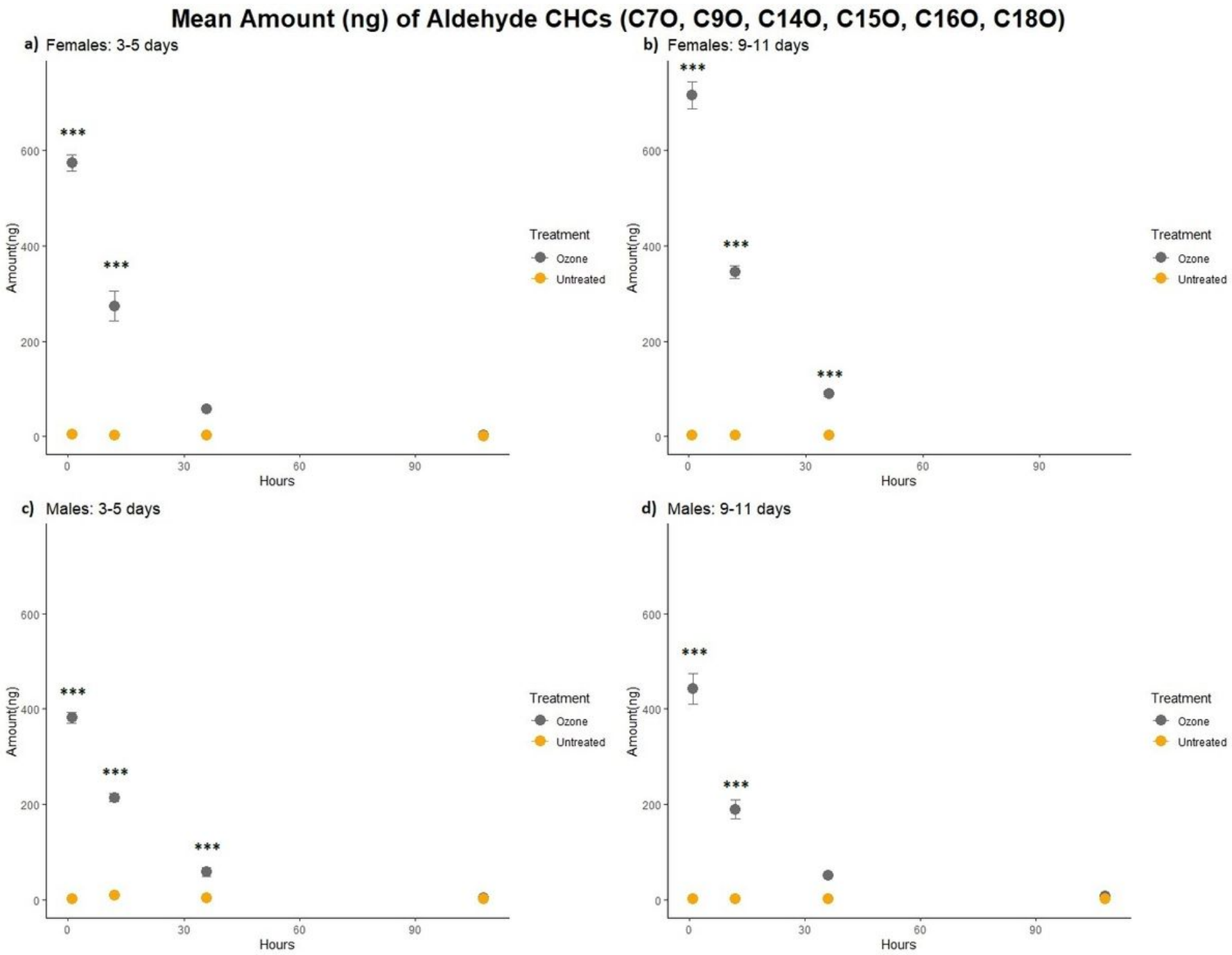

Figure 5

Graphs separated by fly age ( $3-5 \mathrm{~d}, 9-11 \mathrm{~d}$ ). Samples were collected at 1, 12, 36 \& $108 \mathrm{~h}$ after treatment. A significant difference between ozone treated and untreated flies within a CHC extraction hour was marked with $a^{\prime *}{ }^{\prime}(*: 0.05, * *: 0.01, * \star *: 0.001)$. 


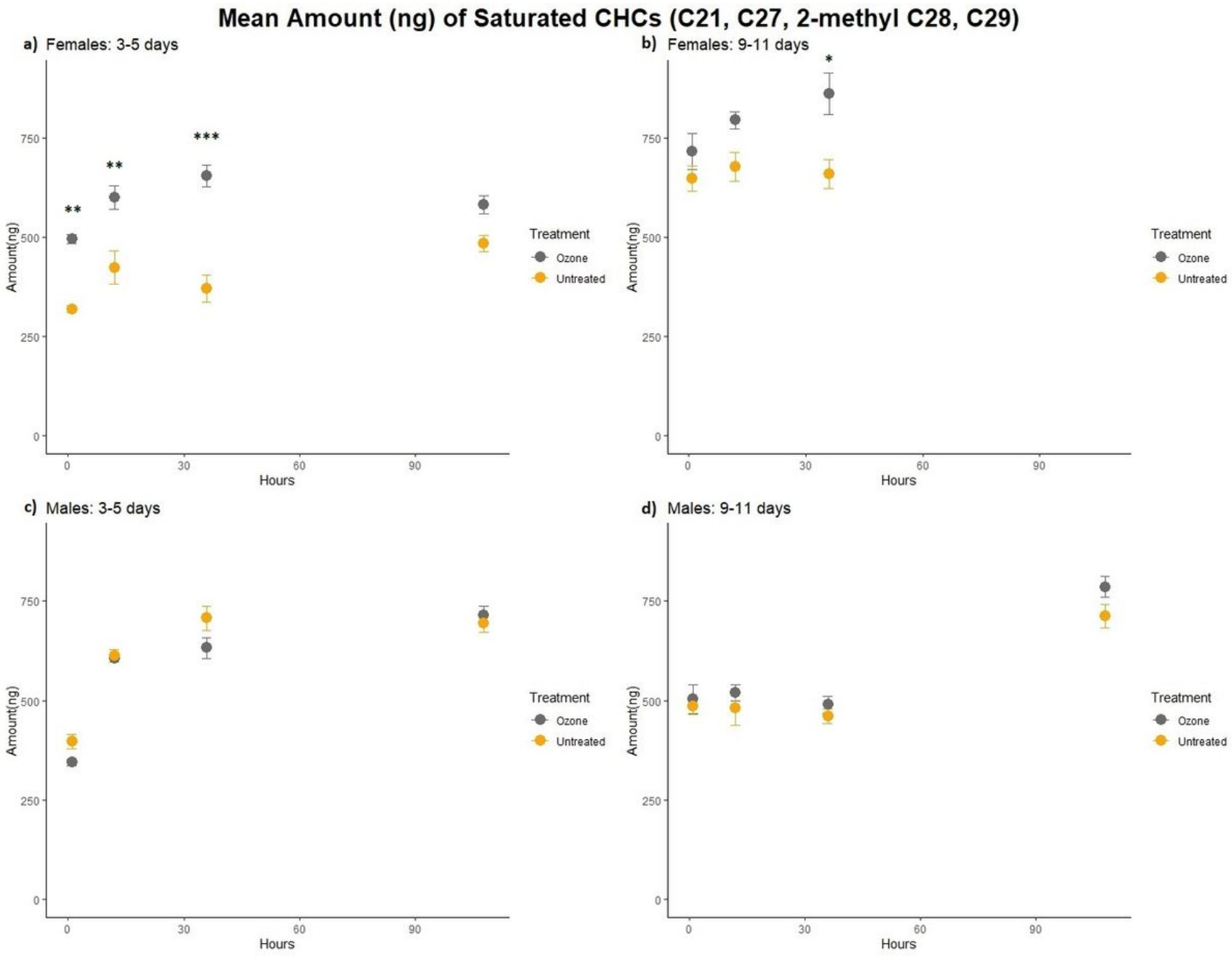

Figure 6

Graphs separated by fly age (3-5 d, 9-11 d). Samples were collected at 1, 12, 36 \& $108 \mathrm{~h}$ after treatment. A significant difference between ozone treated and untreated flies within a CHC extraction hour was marked with $a^{\prime *}{ }^{\prime}(*: 0.05, * *: 0.01, * \star *: 0.001)$. 


\section{Kaplan-Meier Survival Curves: Fly Desiccation Resistance}
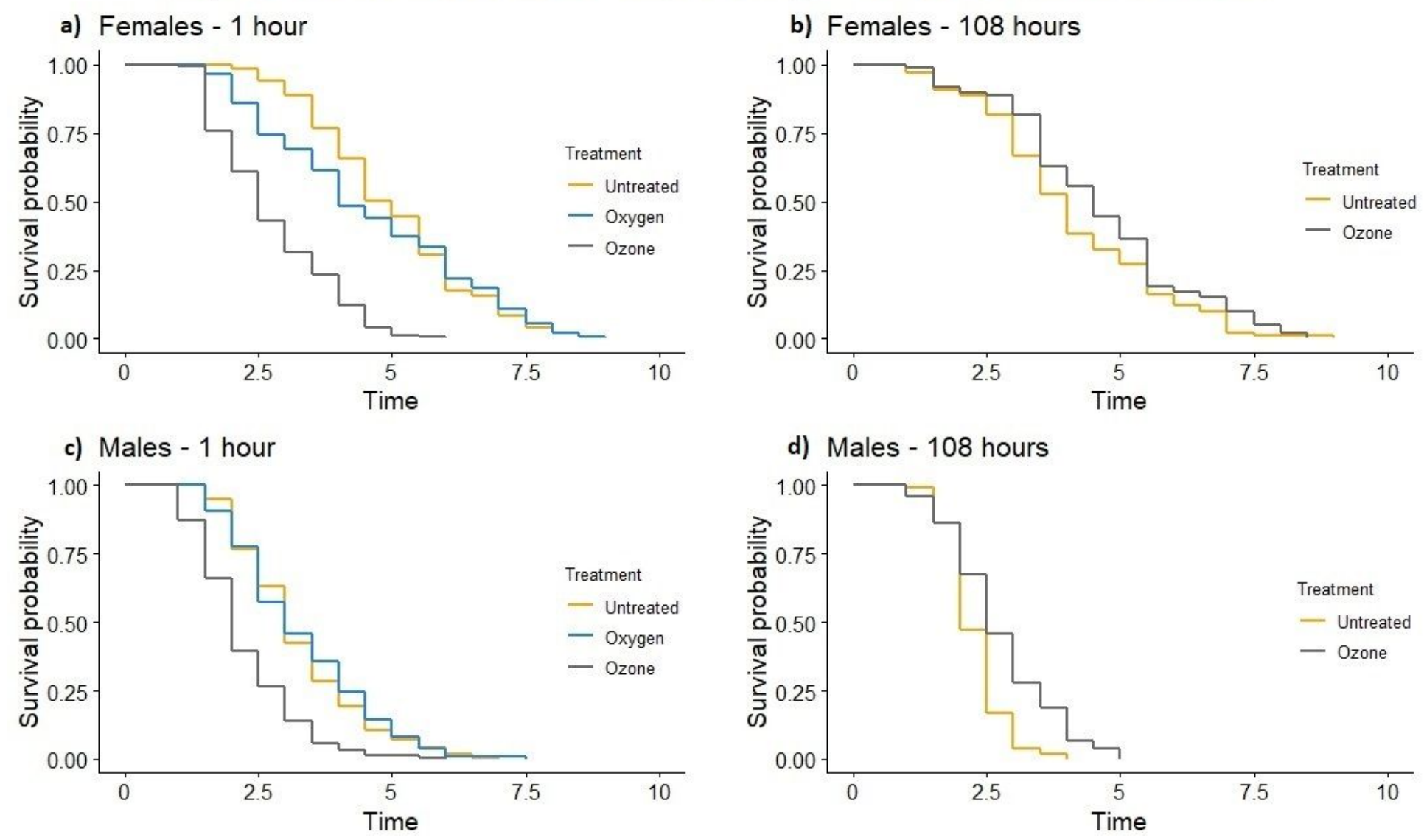

Figure 7

Kaplan-Meier Survival Curves of $3-5 \mathrm{~d}$ old flies at $1 \mathrm{~h}\left(\mathrm{RH}=18.13 \%( \pm 1.54 \%), \mathrm{Temp}=28.89^{\circ} \mathrm{C}( \pm 0.20)\right)$ and $108 \mathrm{~h}(\mathrm{RH}=15.93 \%( \pm 2.12)$, Temp $\left.=28.32^{\circ} \mathrm{C}\left( \pm 0.34^{\circ} \mathrm{C}\right)\right)$ after treatment application. Half-hour sampling periods until 10 hours or all flies died.

\section{Supplementary Files}

This is a list of supplementary files associated with this preprint. Click to download.

- SupplementaryDataJCEsubmission2021V1.pdf 